\title{
Early alterations on photosynthesis-related parameters in Chlamydomonas reinhardtii cells exposed to atrazine: A multiple approach study
}

\author{
Marta Esperanza, Marta Seoane, Carmen Rioboo, Concepción Herrero, Ángeles Cid ${ }^{1}$ \\ Laboratorio de Microbiología, Facultad de Ciencias, Universidad de A Coruña, Campus \\ de A Zapateira, s/n 15071 A Coruña, Spain
}

\section{Science of The Total Environment}

Volumes 554-555, 1 June 2016, Pages 237-245

Received 30 December 2015, Revised 18 February 2016, Accepted 18 February 2016, Available online 5 March 2016

\section{Citation:}

Esperanza M, Seoane M, Rioboo C, Herrero C, Cid Á. Early alterations on photosynthesis-related parameters in Chlamydomonas reinhardtii cells exposed to atrazine: A multiple approach study. Science of The Total Environment, 2016; 554-555: 237-45. doi:10.1016/j.scitotenv.2016.02.175

\section{Highlights}

- Pigment content and chlorophyll a fluorescence decreased in atrazine exposed cells.

- Atrazine induced an increase of reactive oxygen species level in treated cells.

- RNA-Seq analysis showed 9 differentially expressed photosynthesis-related genes.

- Proteomic analysis revealed changes in 5 proteins related to photosynthesis.

\footnotetext{
${ }^{1}$ Corresponding author. angeles.cid@udc.es
} 


\begin{abstract}
Chlamydomonas reinhardtii cells were exposed to a sublethal concentration of the widespread herbicide atrazine for $3 \mathrm{~h}$. Physiological cellular parameters, such as chlorophyll a fluorescence and oxidative stress monitored by flow cytometry and pigments levels were altered in microalgal cells exposed to $0.25 \mu \mathrm{M}$ of atrazine. Furthermore, the effects of this herbicide on C. reinhardtii were explored using "omics" techniques. Transcriptomic analyses, carried out by RNA-Seq technique, displayed 9 differentially expressed genes, related to photosynthesis, between control cultures and atrazine exposed cultures. Proteomic profiles were obtained using ITRAQ tags and MALDI-MS/MS analysis, identifying important changes in the proteome during atrazine stress; 5 proteins related to photosynthesis were downexpressed. The results of these experiments advance the understanding of photosynthetic adjustments that occur during an early herbicide exposure. Inhibition of photosynthesis induced by atrazine toxicity will affect the entire physiological and biochemical states of microalgal cells.
\end{abstract}

\title{
Graphical abstract
}

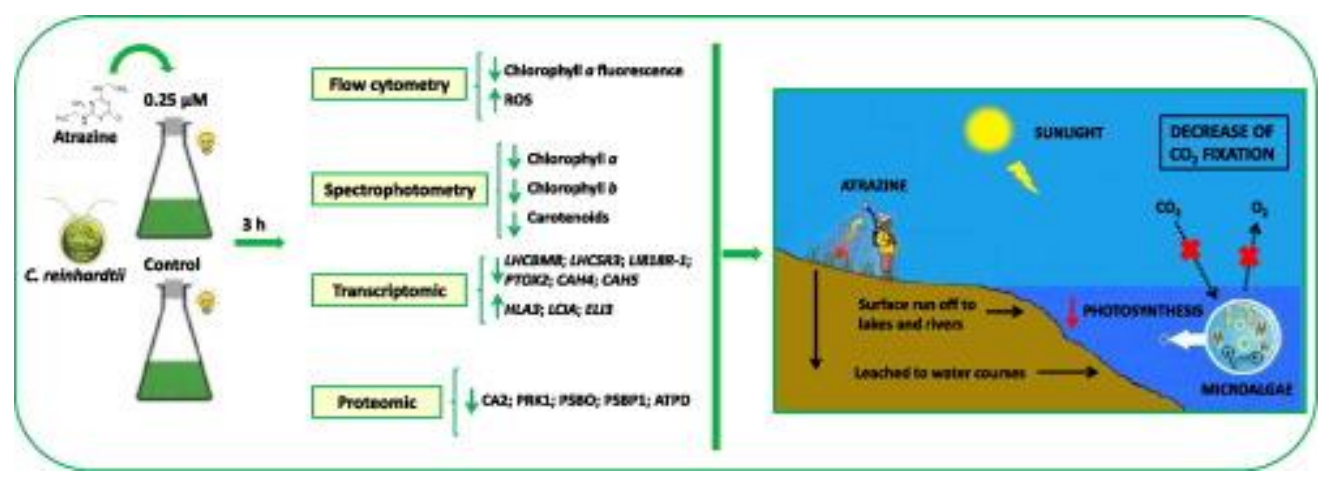

\section{Keywords}

- Microalga;

- Atrazine;

- Flow cytometry;

- iTRAQ;

- MALDI;

- RNA-Seq

\section{Abbreviations}

- a.u., arbitrary units; 
- CCM, carbon concentrating mechanism;

- $\mathrm{Ci}$, inorganic carbon dioxide;

- CHAPS, 3-[(3-Cholamidopropyl)dimethylammonio]-1-propanesulfonate hydrate;

- EB, etidium bromide;

- FCM, flow cytometry;

- FDR, false discovery rate;

- FS,forward scatter light;

- HE, hydroethidine;

- iTRAQ, isobaric tags for relative and absolute quantitation;

- LFC, log2 fold change;

- MALDI-TOF-MS, matrix assisted laser desorption ionization time-of-flight mass spectrometry;

- PSII, photosystem II;

- ROS, reactive oxygen species;

- RPM, reads per million mapped reads;

- SS, side scatter light;

- TCA,tricarboxylic acid cycle

\section{Introduction}

The occurrence of anthropogenic stress-induced chemicals, such as herbicides, in the aquatic environment presents a serious problem. These man-made organic toxicants are released into the aquatic environment and can affect non-target species. One of the herbicides most extensively applied in agriculture all over the world is atrazine. Its widespread application, persistence, and mobility have led to its frequent detection in ground and surface water sources (Hayes et al., 2010) and to list it as priority substance under the European Water Framework Directive as described in Directive 2013/39/EC (European Council, 2013). Atrazine inhibits photosynthesis blocking the photosynthetic electron transport at photosystem II (Rutherford and Krieger-Liszkay, 2001) and thereby energy production drops, preventing $\mathrm{CO}_{2}$ fixation in target and non-target organisms. Atrazine-induced detrimental effects on the aquatic ecosystem and alterations in aquatic community structure have been reported previously (Choi et al., 2012, Didur et al., 2012,Sjollema et al., 2014 and Weiner et al., 2004).

Microalgae have been recommended as test organisms in ecotoxicological studies because of their ecological relevance and sensitivity (Ma et al., 2006). All 
primary producers are the basis of the aquatic food web; therefore it is an interesting study of their photosynthetic state since any disturbance in productivity of the microalgae community can induce direct structural changes in the rest of the ecosystem (Campanella et al., 2001, Martinez et al., 2014 and Rioboo et al., 2007). Regarding toxicity investigations and risk assessment with microalgae, integral endpoints, such as growth and reproduction, are traditionally monitored. However, before these endpoints show a significant change, the exposure may affect other cellular physiological parameters at much lower toxicant concentrations (Nestler et al., 2012).

The photosynthetic state of microalgae can be measured by quantifying the pigment content, which has been used as biomarker of exposure to herbicides in algae (Couderchet and Vernet, 2003). Fluorescence measurements have also been proposed as simple, rapid and sensitive methods to detect the photoinhibitory effects of environmental stressors on phytoplankton (Geoffroy et al., 2007 and Juneau et al., 2002). Flow cytometry (FCM) is an alternative to the standard algal population based endpoints, since it allows the characterization of the microalgal response at a singlecell level close to in vivo conditions. The in vivo chlorophyll a fluorescence of green algae can be used as a tool to detect negative alterations on photosynthesis ( $\mathrm{Bi}$ Fai et al., 2007,Chalifour et al., 2009, Cid et al., 1995, Ekelund and Aronson, 2007, GonzálezBarreiro et al., 2004 and Prado et al., 2011).

Currently, with the development of the omics, new alternatives arise to study the effects of pollutants on microalgae (Dowling and Sheehan, 2006, Esperanza et al., 2015,Jamers et al., 2009 and Monsinjon and Knigge, 2007). Transcriptomics and proteomics can be used to detect and characterize responses to external stimulus, and have a great potential for investigating stress mechanisms and responses affecting growth and other physiological and biochemical endpoints (Jamers and De Coen, 2010, Nestler et al., 2012 and Subramanian et al., 2014), being increasingly applied in ecotoxicology and other fields of biological science. The availability of the sequenced genome of the microalgal species Chlamydomonas reinhardtii, with adequate annotation and metabolic pathway information, facilitates high-throughput analyses of transcriptional and proteomic profiling ( Merchant et al., 2007).

Previous research has demonstrated that $C$. reinhardtii cells exposed to atrazine change their metabolism and get energy mainly by heterotrophic pathways ( Esperanza et al., 2015). In a global climate change scenario with a dramatic increase in $\mathrm{CO}_{2}$ levels, it is very important to know the behavior of carbon fixing organisms. Thus, the aim of the present study was to determine alterations in parameters directly or indirectly related to photosynthesis after only $3 \mathrm{~h}$ of exposure to the herbicide. For this 
purpose, different methodological approaches were applied. First, a traditional spectrophotometric method for the quantification of pigments content was carried out. Additionally, flow cytometry was used to determine chlorophyll a fluorescence and reactive oxygen species level (ROS). Moreover, unlike standard ecotoxicity studies, detailed quantitative transcriptomic profiling of algal cells exposed to atrazine compared with those cultured without herbicide was assessed, looking for changes in the regulation of transcription. Furthermore, a proteomic analysis was carried out to observe early protein alterations due to the stress directly caused by the herbicide.

\section{Materials and methods}

\subsection{Microalgal cultures}

The unicellular green alga C.reinhardtii Dangeard (strain CCAP 11/32A mt +) was obtained from the Culture Collection of Algae and Protozoa of Dunstaffnage Marine Laboratory (Scotland, UK). C. reinhardtii cells were cultured in Tris-minimal phosphate medium ( Harris, 1989) on a rotary shaker set at $150 \mathrm{rpm}$, under controlled conditions: $22 \pm 1{ }^{\circ} \mathrm{C}$ and illuminated with $100 \mu \mathrm{mol}$ photon $\mathrm{m}^{-2} \mathrm{~s}^{-1}$ under a $12: 12 \mathrm{~h}$ light:dark cycle. Cells in mid-logarithmic growth phase were used as inoculum for the different assays. Initial cell density for each experiment was $2 \times 10^{5}$ cells $\mathrm{mL}^{-1}$.

Before each experiment, fresh stock solutions of atrazine were prepared by dissolving the pure compound (Sigma-Aldrich, MW: 215.68) in methanol and filtering through $0.2 \mu \mathrm{m}$ membrane filters. Also control cultures were included, to which only methanol was added. No significant differences between nominal and effective concentration of atrazine were found using a gas chromatography/mass spectrometry analysis.

All cultures were set up in triplicate for $3 \mathrm{~h}$ and at least two independent experiments were carried out for each parameter analyzed. This time point was selected considering previous cytometry studies where the effects of atrazine were analyzed every hour during $24 \mathrm{~h}$ and changes in the cellular metabolic activity and ROS formation were detected after $3 \mathrm{~h}$ of atrazine exposure (unpublished data).

\subsection{Growth measurement}

A growth inhibition test for $C$. reinhardtii using atrazine concentrations ranged from 0.1 to $2 \mu \mathrm{M}$ was carried out to determine the herbicide concentration used for the following determinations of the present study. Cell density was daily determined for $96 \mathrm{~h}$ by counting culture aliquots in the flow cytometer. For absolute cell counting, a suspension of fluorescent polystyrene microspheres (Flow-Count Fluorospheres; 
Beckman Coulter) with known concentration was added as an internal reference to all cell samples. Growth rates $(\mu)$ expressed as day ${ }^{-1}$ were calculated via the formula $\mu=\left[\ln \left(N_{t}\right)-\ln \left(N_{0}\right)\right] / \ln 2\left(t-t_{0}\right)$ where $N_{t}$ is the cell density at time $t$ and $N_{0}$ is the cell density at time 0 . The $96 \mathrm{~h} \mathrm{EC}_{50}$ value for growth was calculated, based on growth rate data, using the computer program CompuSyn (Chou and Martin, 2005).

\subsection{Photosynthetic pigment content}

Pigments were extracted from a concentrated algal sample in a $90 \%$ acetone aqueous solution and determined by measuring the absorbance of the extract using a Shimadzu UV-1700 spectrophotometer at appropriate wavelengths (664, 647 and $480 \mathrm{~nm}$ ). The resulting absorbance measurements were translated to chlorophylls and carotenoids according to Jeffrey and Humphrey (1975) and Strickland and Parsons (1972), respectively. The equations used to calculate the pigment concentrations in the extract are:

Chlorophyll $a=11.93$ A664 -1.93 A647

Chlorophyll $b=20.36$ A647 -5.50 A664

Carotenoids $=4.0 \mathrm{~A} 480$

where total chlorophylls $a$ and $b$ and carotenoids represent the pigment concentrations of extract in $\mathrm{Mg} \mathrm{ml}^{-1}$, and A664, A647 and A480 represent the absorbances measured at 664, 647 and $480 \mathrm{~nm}$, respectively.

\subsection{Flow cytometry analyses}

FCM analyses of $C$. reinhardtii cells were performed on a Beckman Coulter Gallios flow cytometer fitted with $488 \mathrm{~nm}$ and $633 \mathrm{~nm}$ excitation lasers, detectors of forward (FS) and side (SS) light scatter and four fluorescence detectors corresponding to different wavelength intervals: 505-550 nm (FL1), 550-600 nm (FL2), 600-645 nm (FL3) and > $645 \mathrm{~nm}$ (FL4). The 488-nm argon-ion laser was used as excitation source for all the probes assayed. Forward scatter (FS, an estimation of cell size) and red autofluorescence (FL4 channel, an estimation of cell chlorophyll a content) dot-plots were used to characterize the microalgal population, setting gating levels in order to exclude non-microalgal particles. At least 10000 gated cells per sample were collected and analyzed using Kaluza software version 1.1 (Beckman Coulter). All FCM determinations were performed at least twice and duplicate samples were run on the flow cytometer. 


\subsubsection{Inherent cell properties: chlorophyll $a$ fluorescence}

The red autofluorescence of $C$ reinhardtiicells, related to chlorophyll a fluorescent emission, was analyzed to study the potential changes in this pigment content or changes in the functioning of the PSIII. Results were expressed as the mean red fluorescence in the FL4 channel fluorescence intensity in a.u. (Prado et al., 2011).

\subsubsection{Oxidative stress determination}

Oxidative stress in $C$. reinhardtii was evaluated by FCM using determinations of intracellular levels of superoxide anion radical $\left(\mathrm{O}_{2}^{-}\right)$with an oxidation-sensitive fluorescent dye, hydroethidine (HE; Molecular Probes, Inc.). HE was added at a final concentration of $16 \mu \mathrm{M}$ for $30 \mathrm{~min}$ to the cell suspensions $\left(2 \times 10^{5}\right.$ cells $\left.\mathrm{mL}^{-1}\right)$. Results were expressed as the mean orange-ethidium bromide (EB) fluorescence in the FL3 channel fluorescence intensity in a.u. (Prado et al., 2012a).

\subsection{Total RNA extraction and RNA-Seq}

RNA was isolated from control and atrazine exposed $(0.25 \mu \mathrm{M})$ cells after $3 \mathrm{~h}$ of atrazine exposure, using the reagent NZYol (NZYTech), following the procedure described previously in Esperanza et al. (2015).

Then a cDNA library construction and Illumina HiSeq 2000 sequencing were done with the collaboration of AllGenetics \& Biology, SL. A total number of 4 cDNA libraries were constructed, one per sample (2 control and 2 treated samples), using the TruSeq RNA Sample Preparation Kit v2 (Illumina), strictly following the manufacturer's instructions and the pool was sequenced in a HiSeq 2000 PE100 lane.

\subsection{Protein extraction, identification and quantifying}

The protein extraction was carried out following the protocol of Damerval et al. (1986)with some modifications. Cells were harvested by centrifugation to get a pellet of $10 \times 10^{7}$ cells, pellet was resuspended in an extraction buffer $(50 \mathrm{mM}$ Tris $\mathrm{HCl}, \mathrm{pH} 8.8$ with $150 \mathrm{mM} \mathrm{NaCl}$ ), suspended cells were lysed by sonication. For TCA/acetone method, samples were centrifuged and supernatants were taken in fresh tubes and mixed with $10 \%$ of trichloroacetic acid (TCA) in cold acetone with $0.07 \%$ of $\beta$ mercaptoethanol to $0.07 \%$. This mixture was incubated at $20^{\circ} \mathrm{C}$ overnight. After this time, the mixture was centrifuged and the precipitate was washed 3 times with a cold mixture of acetone and $0.07 \%$ of $\beta$-mercaptoethanol, with their respective 
centrifugations. Then the pellet was allowed to dry. Finally, the pellet was resuspended in a solubilization buffer (30 mM Tris, $8 \mathrm{M}$ Urea, $2 \mathrm{M}$ thiourea and $4 \%$ of CHAPS).

Protein concentration of samples was determined by the Bradford method modified byRamagli and Rodriguez (1985). The absorbance was measured in a spectrophotometer at $595 \mathrm{~nm}$ against a blank of solubilization buffer, using Bovine serum albumin (BSA) as a standard.

Trypsin digestion, iTRAQ labeling, liquid chromatography, mass spectrometry, protein identification and quantifying were performed as previously described in Fernández-Puente et al. (2011) and Gayoso et al. (2014). These proteomic analyses were carried out with the collaboration of the Osteoarticular and Aging Research Lab, Proteomics-ProteoRed/ISCIII, INIBIC-Complejo Hospitalario Universitario de A Coruña.

\subsection{Statistical analyses}

For the photosynthetic pigment content and FCM data, mean values \pm standard deviation (SD) of at least two experiments were statistically analyzed by an overall oneway analyses of variance (ANOVA) using SPSS Statistic software (version 21.0, SPSS, IBM). A p-value of $<0.05$ was considered statistically significant. When significant differences were observed, means of treated cultures were compared with control means using the Dunnett test.

For the RNA-Seq data, the bioinformatic analysis was carried out by ECSEQ Bioinformatics, using the "edgeR 3.8.5" program for the analysis of differential expression of the genes. Only genes with a "false discovery rate" (FDR) $\leq 0.01$ and a " $\log _{2}$ fold change" (LFC) $\geq 1$ or $\leq-1$ were selected.

For proteomic analysis, the normalization tools and statistical package from ProteinPilot 4.0 software (AB Sciex) were employed. A stringent $>95 \%$ confidence interval was applied (equivalent to ProteinPilot Unused score $>1.3$ ). Spectra were searched against the Chlamydomonas protein database v5.3 (19,529 Protein Sequences downloaded from Phytozome). After searching, protein IDs that had a ProteinPilot Unused Score of at least 1.3 (corresponding to a 95\% Confidence Interval) were accepted. The ProteinPilot software also calculated a confidence percentage, the unused score, which reflects the probability of a hit being a "false positive," at a 95\% confidence. Although this software automatically accepts all peptides with an identification level of $>1 \%$, only proteins having at least one peptide above the $95 \%$ confidence level were initially recorded. Searches against a concatenated database containing both forward and reversed sequences allowed the false discovery rate to be kept at $1 \%$. Data were normalized for loading error by bias and the background 
correction was calculated using the Pro Group algorithm (ABSciex). A $p \leq 0.05$ or a ratio of $\geq 1.2$ or $\leq 0.8$ was considered significant (over- or underexpressed).

Then, differentially expressed genes and proteins were classified manually by categories of functions previously described in Hemschemeier et al. (2013), using information from Ensembl Plants 22 C.reinhardtii v3.1. Furthermore, GO (Gen Ontology) enrichment analyses were performed using the Algal Functional Annotation Tool at http://pathways.mcdb.ucla.edu/algal/index.html (Lopez et al., 2011).

\section{Results and discussion}

\subsection{Growth}

Growth data indicated that atrazine treatment induced a significant $(p<0.05)$ inhibitory effect on the proliferation of $C$. reinhardtii in a concentration-dependent manner ( Table 1$)$. Control cultures showed significantly $(p<0.05)$ higher cell numbers per $\mathrm{mL}$ medium and higher average growth rates than the atrazine exposed population after $96 \mathrm{~h}$ (Table 1). The $\mathrm{EC}_{50}$ for growth after $96 \mathrm{~h}$ value, based on growth rate data was $0.231 \mu \mathrm{M}$. Then, the sublethal atrazine concentration used in the following analyses of the present study was $0.25 \mu \mathrm{M}$, a concentration close to this $96 \mathrm{~h}$ $\mathrm{EC}_{50}$ value.

Table 1. Effect of atrazine on the growth of $C$. reinhardtii cells after $96 \mathrm{~h}$ of exposure. Values are shown as mean $\pm S D$ of experimental triplicates. Asterisks $\left(^{*}\right)$ indicate significant differences $(p<0.05)$ versus non-treated control.

\begin{tabular}{l|l|l|}
$\begin{array}{l}\text { Atrazine } \\
(\mu \mathrm{M})\end{array}$ & $\begin{array}{l}\text { Cell density } \\
\left(\text { cells } \times 10^{4} \mathrm{~mL}^{-1}\right)\end{array}$ & $\begin{array}{l}\text { Growth rates }(\mu) \\
\left(\text { day }^{-1}\right)\end{array}$ \\
\hline $\begin{array}{l}\text { Control } \\
457.50 \pm 20.30\end{array}$ & $1.13 \pm 0.02$ \\
\hline 0.1 & $256.00 \pm 11.46^{*}$ & $0.92 \pm 0.02^{*}$ \\
\hline 0.25 & $74.90 \pm 1.30^{*}$ & $0.48 \pm 0.01^{*}$ \\
\hline 0.5 & $56.20 \pm 0.85^{\star}$ & $0.37 \pm 0.01^{*}$ \\
\hline 1 & $22.50 \pm 0.40^{*}$ & $0.04 \pm 0.00^{*}$ \\
\hline 2 & $20.30 \pm 0.30^{*}$ & $0.01 \pm 0.00^{*}$
\end{tabular}

\subsection{Photosynthetic pigment content and chlorophyll a fluorescence}

After $3 \mathrm{~h}$ of exposure to a sublethal atrazine concentration $(0.25 \mu \mathrm{M})$, chlorophyll $a$ and total carotenoid contents of $C$. reinhardtii biomass were significantly reduced $(p<0.05)$ with respect to control cultures, $26.7 \%$ and $29.4 \%$, respectively (Fig. 
1). However a non-significant reduction $(19.1 \%, p>0.05)$ in the cellular amount of chlorophyll $b$ was observed in cultures exposed to atrazine ( Fig. 1).

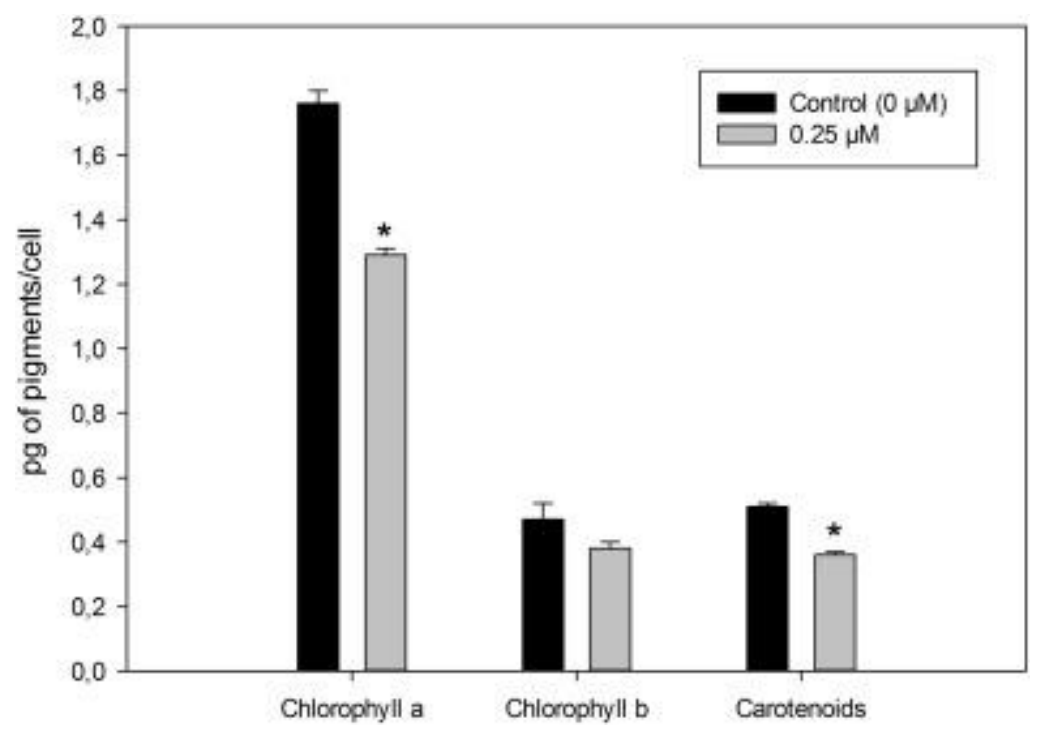

Fig. 1. Photosynthetic pigment content of $C$. reinhardtii cells in control cultures and atrazine exposed $(0.25 \mu \mathrm{M})$ cultures at $3 \mathrm{~h}$. Photosynthetic pigment content values are shown as mean \pm SD of experimental duplicates, expressed as pg of pigments per cell. Asterisks ${ }^{*}$ ) indicate significant differences $(p<0.05)$ versus non-treated control.

FCM data showed a significant reduction $(p<0.05)$ of $16.6 \%$ of the chlorophyll afluorescence $(2065 \pm 35.36$ a.u. $)$ with respect to control cultures (2475 \pm 77.78 a.u.) after $3 \mathrm{~h}$ of exposure to the herbicide (Fig. $2 \mathrm{~A}$ ).
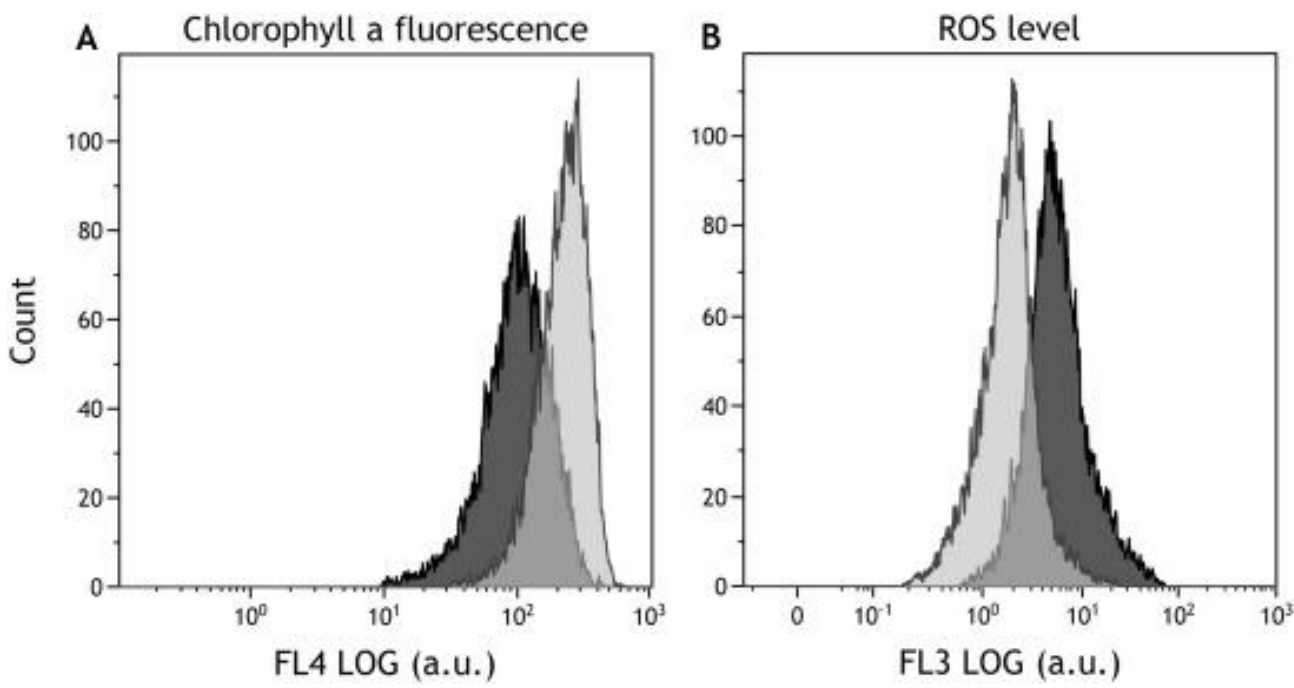

Control

$0.25 \mu \mathrm{M}$

Fig. 2. Overlay histograms of flow cytometric analysis of chlorophyll a autofluorescence (A) and intracellular levels of superoxide anion radical $(B)$ of $C$. reinhardtii cells in control cultures and atrazine exposed $(0.25 \mu \mathrm{M})$ cultures at $3 \mathrm{~h}$. (Y-axis: count; $X$-axis: fluorescence intensity in arbitrary units, a.u.).

Chlorophyll a fluorescence is a function of the cell pigment content and the photochemical activity of PSII in the photosynthetic electron transport chain ( Franklin 
et al., 2001). Thus, in this study, the observed reduction of the autofluorescence can be explained by the decrease in cellular pigment content.

Furthermore, chlorophyll a fluorescence emission analysis of PSIl from the photosynthetic apparatus of algae makes possible the characterization of the effects and modes of action of different kinds of environmental stressors and water pollutants such as herbicides ( Brack and Frank, 1998). Obtained results indicated a reduction of photosynthetic activity and this is related to the atrazine mechanism of action on the D1 protein of PSII ( Chalifour et al., 2009 and Didur et al., 2012). Photosynthesis inhibition induced by atrazine toxicity will affect the entire physiological state and cell growth process ( Bi Fai et al., 2007 and Esperanza et al., 2015).

These results, decrease in the cellular pigment content and the reduction of the chlorophyll a fluorescence caused by atrazine ( Fig. 1 and Fig. 2A), are in accordance with results obtained in previous studies in which it is reported that microalgal cells, under the stress induced by this herbicide, change their photoautotrophic metabolism, inefficient under these conditions, to an heterotrophic metabolism ( Esperanza et al., 2015 and González-Barreiro et al., 2004).

\subsection{Oxidative stress}

In order to test the relationship between atrazine treatment and oxidative stress induction in $C$. reinhardtii, FCM analysis of reactive oxygen species (ROS) generation level was evaluated. The exposure to atrazine caused a remarkable accumulation of ROS in $C$. reinhardtii cells, resulting in a significant increase $(p<0.05)$ in the intracellular level of superoxide anion radical $\left(\mathrm{O}_{2},\right)$ in treated cultures (46.95 \pm 0.83 a.u.) with respect to control cultures (34.70 \pm 0.99 a.u.) (Fig. $2 B$ ). This increase in cellular ROS level is related to the reduction of pigments and autofluorescence, since it has been well documented that a photosynthetic efficiency decrease can enhance ROS production in microalgal cells, followed by oxidative damages and function abnormalities (Liu et al., 2012).

Although ROS were classically considered toxic metabolic byproducts that ultimately lead to cell death, it is now recognized that ROS act as central secondary messengers involved in compartmentalized signaling networks (Rosenwasser et al., 2014). This function suggests that cells have evolved strategies to utilize ROS as biological signals that control various genetic stress programs. This interpretation is based on the unstated assumption that a given ROS can interact selectively with a target molecule that perceives the increase in ROS concentration, and then translates this information into a change of gene expression, such as changes in transcriptional activity (Laloi et al., 2004). 
Results obtained showed a significant increase in intracellular ROS levels in the cultures exposed to atrazine (Fig. 2B). Toxic action involving ROS formation and oxidative stress have been reported in ecotoxicological studies with unicellular algae exposed to atrazine (Qian et al., 2009 and Mofeed and Mosleh, 2013), paraquat (Jamers and De Coen, 2010,Nestler et al., 2012, Prado et al., 2012a and Prado et al., 2012b), and metals (Melegari et al., 2013 and Perreault et al., 2012). C. reinhardtii is sensitive to the oxidative action of atrazine and this can be related to the decrease observed in the cellular content of chlorophyll, as has been reported in plants ( Ekmekci and Terzioglu, 2005).

In a previous study with atrazine the cellular activity of microalgal cells was affected significantly at tested concentration, however non-significant changes in cell viability were observed (Esperanza et al., 2015). ROS generated by the mechanism of action of atrazine, as described above, provoked redox misbalances and alterations in gene regulation and protein synthesis, and therefore a general decrease in the cellular activity.

\subsection{Transcriptomic analyses}

Obtained RNA-Seq data showed 185 differentially expressed genes (FDR $\leq 0.01$ and LFC $\geq 1$ or $\leq-1$ ) between control cultures and cultures exposed to atrazine $(0.25 \mu \mathrm{M})$ at tested time $(3 \mathrm{~h})$. These genes were classified manually in 13 categories of functions: photosynthesis, metabolism, gene expression, energy, amino acids, cell cycle, redox, lipids, regulation, ROS and stress, proteases, other and unknown (Hemschemeier et al., 2013). Of this amount of genes, 124 showed a reduction in their expression, while 61 genes showed an increase (Fig. 3).

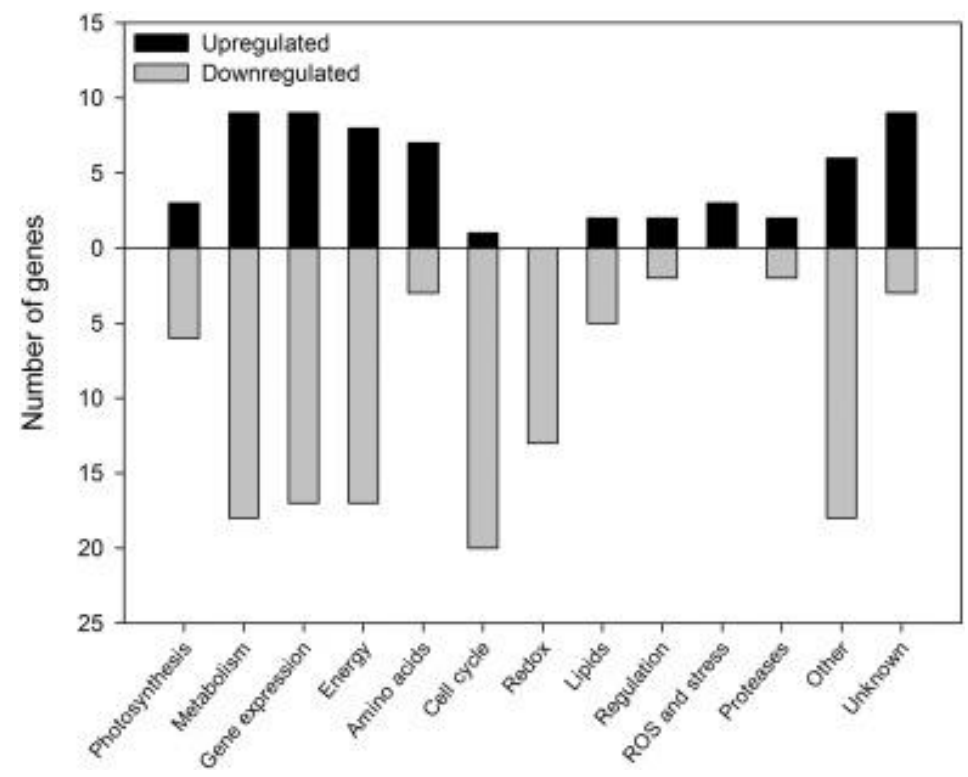


Fig. 3. Differentially expressed genes (FDR $\leq 0.01$ and LFC $\geq 1$ or $\leq-1$ ) after $3 \mathrm{~h}$ of exposure to $0.25 \mu \mathrm{M}$ of atrazine with respect to the control divided into 13 categories. Separated by a horizontal axis the genes upregulated are in the top and the downregulated are in the bottom.

Besides the large number of altered genes, this study was only focused on those related directly or indirectly to photosynthesis processes (9). Within this category, 6 of the 9 genes (LHCBM8, LHCSR3, LI818R-1, PTOX2, CAH4 and CAH5) were significantly downregulated and 3 were significantly upregulated (HLA3, LCIA and ELI3) ( Table 2).

Table 2. Differentially expressed genes related to photosynthesis of $C$. reinhardtii. Comparison of transcript abundances and fold-changes in cultures exposed to $0.25 \mu \mathrm{M}$ of atrazine for $3 \mathrm{~h}$ vs. control cultures. For each comparison, a gene was deemed differentially expressed if it fitted the following criteria: significant " $\log _{2}$ fold change" (LFC $\leq-1$ or $\geq 1$ ) and significant "false discovery rate" (FDR $\leq 0.01$ ). RPM means "Reads per million mapped reads".

\begin{tabular}{|c|c|c|c|c|c|c|}
\hline Gene ID & $\begin{array}{l}\text { Gene } \\
\text { name }\end{array}$ & $\begin{array}{l}\text { Average } \\
\text { RPM } \\
\text { (treatment) } \\
3 \mathrm{H}\end{array}$ & $\begin{array}{l}\text { Average } \\
\text { RPM } \\
\text { (control) } \\
3 \mathrm{H}\end{array}$ & $\begin{array}{l}\text { Log }_{2} \text { fold } \\
\text { change } 3 \mathrm{H}\end{array}$ & FDR 3H & Description \\
\hline \multicolumn{7}{|c|}{ Downregulated } \\
\hline 205752 & LHCBM8 & 266.80 & 595.64 & -1.05 & 0.000119 & $\begin{array}{l}\text { Chlorophyll } a- \\
b \text { binding protein of } \\
\text { LHCII }\end{array}$ \\
\hline 184730 & LHCSR3 & 24.00 & 168.52 & -2.70 & $4.36 e-43$ & $\begin{array}{l}\text { Stress-related } \\
\text { chlorophyll } a / b \text { bindin } \\
\text { g protein } 3\end{array}$ \\
\hline 184724 & LI818R-1 & 8.78 & 29.62 & -1.64 & $5.53 e-12$ & $\begin{array}{l}\text { Stress-related } \\
\text { chlorophyll a/b } \\
\text { binding protein } 1\end{array}$ \\
\hline 205757 & PTOX2 & 24.18 & 67.80 & -1.37 & $1.92 e-07$ & $\begin{array}{ll}\text { Alternative } & \text { oxidase, } \\
\text { plastid } & \text { terminal } \\
\text { oxidase } 2 & \end{array}$ \\
\hline 24552 & $\mathrm{CAH} 4$ & 272.75 & 601.41 & -1.03 & $2.23 e-05$ & $\begin{array}{l}\text { Mitochondrial } \\
\text { carbonic anhydrase, } \\
\text { beta type }\end{array}$ \\
\hline 196876 & CAH5 & 147.79 & 317.96 & -1.00 & 0.000493 & $\begin{array}{l}\text { Mitochondrial } \\
\text { carbonic anhydrase, } \\
\text { beta type }\end{array}$ \\
\hline \multicolumn{7}{|c|}{ Upregulated } \\
\hline 134058 & $H L A 3$ & 348.89 & 161.78 & 1.21 & 0.00172 & $\begin{array}{l}\text { ABC transporter, } \\
\text { multidrug resistance- } \\
\text { related proteins } \\
\text { (MRP) subfamily }\end{array}$ \\
\hline
\end{tabular}




\begin{tabular}{|l|l|l|l|l|l|}
\hline LCIA & 94.31 & 29.03 & 1.82 & $1.48 \mathrm{e}-10$ & $\begin{array}{l}\text { Low- } \mathrm{CO}_{2} \text {-inducible } \\
\text { membrane protein }\end{array}$ \\
\hline ELI3 & 5.48 & 2.22 & 1.40 & 0.000105 & $\begin{array}{l}\text { Early light inducible } \\
\text { chlorophyll a/b }\end{array}$ \\
\hline 148916 & & & & & \\
binding protein
\end{tabular}

The LHCBM8, LHCSR3 and LI818R-1 transcripts encode early light inducible (LHCBM8) and stress-related (LHCSR3 and LI818R-1) chlorophyll a/b binding proteins that play a key role in the light-harvesting complex. In this study all of these transcripts were significantly downregulated (Table 2). In eukaryotic oxygenic photosynthetic organisms, light-harvesting chlorophyll $a / b$ binding proteins function in the collection and transfer of light energy to the reaction centers of the photosystems II and I. Additionally these proteins are also involved in light dissipation and energy quenching. Therefore, light-harvesting proteins are important components of the photosynthetic machinery that optimize photosynthetic function and minimize photooxidative damage in response to light quantity and quality ( Stauber et al., 2003). Maruyama et al. (2014) showed that the transcription of the LHCSR3 gene, the most downregulated in the current study ( Table 2), was suppressed by treatment with a photosystem II inhibitor (DCMU). Bonente et al. (2011) have also shown that LHCSR3, essential for energy quenching in $C$. reinhardtii, is a pigment-binding protein with the properties of a constitutive quencher. LI818R-1 protein has been suggested to play a role in protecting chlorophyll proteins from excitation pressure under low $\mathrm{CO}_{2}$ as well as high light conditions ( Iwai et al., 2007 and Richard et al., 2000). The decrease in the level of transcription of these genes in treated cells is in accordance with the mechanism of action of atrazine that inhibits PSII and the decrease in chlorophyll a content and its fluorescence ( Figs. 1 and 2A).

The PTOX2 transcript encodes a plastid terminal oxidase 2, the oxidase most predominantly involved in chlororespiration in Chlamydomonas species (HouilleVernes et al., 2011). Transcriptomic data revealed that also the amounts of PTOX2 decrease significantly in this study ( Table 2). Chlororespiration has been defined as an alternative respiratory electron transport chain in interaction with the photosynthetic electron transport chain in thylakoid membranes of chloroplasts (Peltier and Cournac, 2002). It works as a valve to dissipate excess NADPH and maintain redox homeostasis. Chlororespiration involves two proteins that have been recently identified inChlamydomonas: a NADPH dehydrogenase (NDA2), and a plastid terminal oxidase (PTOX2). NDA2 reduces plastoquinones from NADPH, and PTOX2 regenerates oxidized plastoquinones at the expense of $\mathrm{O}_{2}$. Activity of these two 
chloroplast enzymes, which act in tandem, results in the oxidation of NADPH and the consumption of $\mathrm{O}_{2}$ (Johnson and Alric, 2013). Downregulation of PTOX2 and the observed ROS production can be related to the mechanism of action of atrazine because, as mentioned before, this herbicide blocks the photosynthetic electron transfer to the plastoquinone pool, leading to production of triplet chlorophyll and $\mathrm{O}_{2}^{-}$. PTOX2 is also important for carotenoid biosynthesis during chloroplast biogenesis because its activity prevents the over-reduction of the plastoquinone pool. Plants without this enzyme exhibit phenotypes of variegated leaves with white patches because the carotenoid synthesis pathway slows down due to the lack of oxidized plastoquinone which oxidizes phytoene, a carotenoid intermediate (Carol and Kuntz, 2001). Therefore, the observed downregulation of thePTOX2 transcript could be related to the decrease in the carotenoid contents ( Fig. 1). A lack of PTOX2 indirectly causes photodamage during plastid development because protective carotenoids are not synthesized (Aluru and Rodermel, 2004). Excess light captured by the lightharvesting complex of PSII is dissipated by carotenoids. The lack of sufficient amount of carotenoids and chlorophyll (Fig. 1) generates reactive oxygen radicals which in turn lead to the photooxidation of plastid components (Aluru and Rodermel, 2004). Hence, the decreased amounts of this transcript could also be related to the accumulation of ROS observed in this study in the cultures treated with atrazine (Fig. 2B).

The transcripts $\mathrm{CAH} 4$ and $\mathrm{CAH} 5$ encode beta carbonic anhydrases (CAs) which are zinc-containing metalloenzymes that catalyse the reversible interconversion of $\mathrm{CO}_{2}$ and $\mathrm{HCO}_{3}^{-}$, and these two transcripts were also significantly downregulated in cultures exposed to atrazine $(0.25 \mu \mathrm{M})$ for $3 \mathrm{~h}$ with respect to control cultures (Table 2). Although these beta carbonic anhydrases are localized in the mitochondria (Eriksson et al., 1995 and Eriksson et al., 1996), they could affect chloroplast related processes, being linked to the carbon concentrating mechanism (CCM) (Moroney and Ynalvez, 2007). The role of these mitochondrial CAs has been suggested as buffering matrix $\mathrm{H}^{+}$upon the initiation of photorespiration when the cells are transferred from high to low $\mathrm{CO}_{2}$ conditions (Eriksson et al., 1996). When subjected to low- $\mathrm{CO}_{2}$ environments, mitochondria are found to migrate around the periphery of the chloroplast, and CAH4 and $\mathrm{CAH} 5$ may function in the capture of $\mathrm{CO}_{2}$ escaping the chloroplast, rapidly converting these molecules to $\mathrm{HCO}_{3}^{-}$, which can be better retained by the cell ( Giordano et al., 2003, Moroney et al., 2011 and Raven, 2001). Atrazine exposed cells acts like cells grown in dark conditions changing their autotrophic metabolism (Esperanza et al., 2015), according to results obtained by Hemschemeier et al. (2013) when C. reinhardtii cells were studied under anoxic and dark conditions. Since 
the CCM is only activated in the presence of light, enzymes related to this process, such as $\mathrm{CAH} 4$ and $\mathrm{CAH} 5$, were expected to be downregulated ( Tirumani et al., 2014).

RNA-Seq data also revealed the upregulation of three transcripts (HLA3, LCIA and ELI3) ( Table 2). HLA3 and LCIA were identified as Ci transporters candidates. HLA3 (high light-induced gene 3, also known as Mrp1 for multidrug resistance-related protein 1) has been annotated as a putative ATP-binding cassettetype transporter, containing a single ABC-MRP domain and it was predicted to be localized to the plastid membrane (Winck et al., 2013). LCIA, also known as Nar1.2, was identified as a limiting- $\mathrm{CO}_{2}$-inducible gene in a large-scale analysis of gene expression profiles in $C$. reinhardtii (Miura et al., 2004). LCIA has six predicted transmembrane domains, and possesses a domain of the formate/nitrite transporter protein family. Members of this protein family have been identified in the genome of prokaryotes, yeast and green algae Chlamydomonas, Chlorella and Volvox. It has been reported $H L A 3$ increases in $C$. reinhardtii, under low $\mathrm{CO}_{2}$ conditions (Jungnick et al., 2014). LCIA was proposed as a candidate Ci transporter localized in the chloroplast membrane of Chlamydomonas cells (Winck et al., 2013) rather than a nitrite transporter, as are the remaining $N A R 1$ gene family members of $C$. reinhardtii, because the expression of $L C I A$ is regulated by $\mathrm{CO}_{2}$ irrespective of the nitrogen source ( Miura et al., 2004 and Spalding, 2008). RNAi strains with reduced expression of both $L C I A$ and $H L A 3$ grew poorly on low $\mathrm{CO}_{2}$ (Duanmu et al., 2009).

The EL/3 transcript encodes an early light inducible chlorophyll $a / b$ binding protein (Table 2). ELIs such as ELI3 encode polypeptides with high sequence similarity to the early light-induced proteins (Elips) characterized in vascular plants and to the Cbr protein from Dunaliella bardawil. Biochemical studies suggest that Elips bind both chlorophylland lutein ( Adamska, 1997 and Adamska, 2001) and they might function in a photoprotective manner, possibly scavenging chlorophyll molecules during the turnover of light-harvesting complexes (Adamska, 1997 and Adamska, 2001). Hutin et al. (2003)showed that Elips function in photoprotection, either by binding free chlorophyll or chlorophyll-degradation products, or by promoting the proper assembly of pigment protein complexes during exposure of cells to high light. It has been hypothesized that they play a protective role either by transiently binding the excited free chlorophyll molecules as transient pigment carriers and/or by binding xanthophyll pigments to dissipate the excess absorbed light energy (Adamska, 2001, Havaux, 2003, Hutin et al., 2003, Król et al., 1999 and Montané and Kloppstech, 2000). Cbr, the $D$. bardawihomologue of Elips, is induced when algal cells are exposed to stressful conditions, such as high light treatment, sulfur starvation, norflurazon treatment (norflurazon blocks carotenoid biosynthesis) ( Lers et al., 1991 and Levy et al., 1993) or 
atrazine treatment. This study also shows that atrazine causes an induction of EL/3 transcript ( Table 2). More recently, ELIPS in Arabidopsis was proposed to physiologically function in the regulation of chlorophyll concentration in thylakoid membranes: it acts as a chlorophyll sensor that modulates 5-aminolevulinic acid biosynthesis to prevent accumulation of free chlorophyll and hence prevent photooxidative stress ( Tzvetkova-Chevolleau et al., 2007 and Zhang et al., 2012).

Transcriptomic results showed that the amounts of various transcripts related to photosynthesis decreased in the cultures exposed to atrazine with respect to control cultures (Table 2). Transcripts encoding for light-harvesting, carbon concentrating mechanism or other chlorophyll binding proteins were reduced in abundance. The general downregulation of genes associated with chlorophyll binding or biosynthesis is supported by the lower chlorophyll contents (Fig.1) (Chekounova et al., 2001 and Duanmu et al., 2013). Hemschemeier et al. (2013) also found this reduction in pigment content in dark-grown $C$. reinhardtii cells. Furthermore, the reduced abundances of transcripts related to photosynthesis would be reflected by the status of the photosynthetic apparatus and the PSII as we can see in FCM results, which show a decrease in the chlorophyll a fluorescence ( Fig. 2A). C. reinhardtii cells exposed to atrazine had lower chlorophyll contents, and exhibited reduced autofluorescence. However, there were a few photosynthesis-related transcripts whose amounts increased ( $H L A 3, L C I A$ and ELI3; Table 2). In view of these data, it can be assumed that the few photosynthetic transcripts that were accumulated have a role in the acclimation of a photosynthetic organism to the stress provoked by the herbicide.

\subsection{Proteomic analyses}

RNA-Seq technique allows the study of a rapid response to stress, but it is also important to consider the early alterations in the proteome profile. For this purpose, an iTRAQ peptide labeling experiment was made. Relative abundance of 12 proteins were significantly decreased ( $p \leq 0.05$ and expression ratio $\leq 0.8)$ in cultures exposed to atrazine $0.25 \mu \mathrm{M}$, being 5 of them proteins related to photosynthesis (CA2, PSBO, PSB1, PRK1, ATPD) (Table 3).

Photosynthesis and carbon assimilation were also affected by atrazine at the proteomic level. Carbonic anhydrase (CA2 or CAH2), with carbonate dehydratase activity, was significantly decreased in treated cells (Table 3). This protein catalyzes the interconversion between carbon dioxide and bicarbonate, playing an important role in carbon fixation, metabolism and Calvin cycle. The interpretation of the physiological function of carbonic anhydrases (CAs) in unicellular algae is difficult due to the presence of multiple CA isozymes and different localizations, as commented above, 
but at least two alpha CAs are found in the periplasmic space of Chlamydomonas, namely $\mathrm{CAH} 1$ and $\mathrm{CAH} 2$. These proteins facilitate the diffusion of $\mathrm{Ci}$ to the plasma membrane (Moroney et al., 2011). In microalgae that possess a carbon concentrating mechanism (CCM), the enzyme located in the chloroplast stroma that has carbonate dehydratase activity (CA2), is needed to convert the accumulated $\mathrm{H}_{2} \mathrm{CO}_{3}$ to $\mathrm{CO}_{2}$, the substrate for Rubisco (Badger and Price, 2003 and Huang et al., 2011). Uptake of inorganic carbon as $\mathrm{CO}_{2}$ or bicarbonate is facilitated in Chlamydomonas across all membrane systems of the cell by CCM acting in concert with carbonic anhydrase (Förster et al., 2006).

Table 3. Comparison of photosynthesis-related protein abundances in cultures exposed to $0.25 \mu \mathrm{M}$ of atrazine for $3 \mathrm{~h}$ vs. cultures control of $C$. reinhardtii cells. For each comparison, a protein was deemed differentially downregulated if it met the following criteria: 1$)$ significant ratio $(\leq 0.8)$ and 2$)$ significant $p$ value $(p \leq 0.05)$.

\section{$0.25 \mu \mathrm{M}$ :control}

Accession

number

Protein name

Description

Ratio $p$-Value

CA2

P93109

A8IYP4

PRK1, 195910

Periplasmic carbonic anhydrase, alpha

$0.2466 \quad 0.0032$ type

A8J0E4

PSBO, 130316

Phosphoribulokinase

$0.4613 \quad 0.0029$

Oxygen-evolving enhancer protein 1 of $0.5495 \quad 0.0010$ photosystem II

PSBP1, 33411

Oxygen-evolving enhancer protein 2 of

$0.4571 \quad 0.0055$

A8IYH9 photosystem II

ATPD, atpH, Chloroplast ATP synthase delta chain

$0.4529 \quad 0.0430$

A8JF15 132678

The enzyme phosphoribulokinase (PRK1) also decreases in cultures exposed to atrazine (Table 3). PRK1 is recognized as an important regulatory protein in the process of carbon fixation. Unique to the Calvin cycle, PRK catalyzes the ATPdependent phosphorylation of ribulose 5-phosphate, thereby regenerating ribulose 1,5bisphosphate (RuBP), the $\mathrm{CO}_{2}$ acceptor molecule and substrate for ribulose 1,5bisphosphate carboxylase/oxygenase (Rubisco) (McKay et al., 1991).

Moreover, the presence of both proteins encoding PSIl components and subunits of the oxygen-evolving complex (OEC) of PS-II (PsbO, PsbP1) were also reduced following herbicide exposure. Furthermore, the levels of the chloroplastic ATP synthase subunit (ATPD), with proton-transporting ATP synthase activity was found to be reduced in cultures exposed to atrazine with respect to the control cultures (Table 3). Thus, under atrazine stress, the algal cells have diminished photosynthetic capacity due to the reduction of components of photosystem II, as well as the plastidic ATP- 
generating system and this finding is in accordance with the observed significant decrease in the chlorophyll a fluorescence and pigments ( Fig. 1 and Fig. 2A).

Gene expression is controlled globally and at multiple levels in response to environmental stress (Lackner et al., 2012). As being indicated before, in the aim of this study, changes in the proteomic profile detected after only $3 \mathrm{~h}$ of exposure are mainly due to the stress directly caused by the herbicide on proteins, and not due to a change in the regulatory processes of gene expression.

In Esperanza et al. (2015), a significant decline in cellular activity was also observed in the $C$. reinhardtii cells exposed to atrazine and this may be also related to a reduction in the photosynthetic activity ( Fig. 1 and Fig. 2A). C. reinhardtii cells under atrazine stress conditions could change their photosynthetic metabolism to a heterotrophic one, because this herbicide exerts its mechanism of action on the photosystem II ( Marchetti et al., 2013 and Rutherford and Krieger-Liszkay, 2001), thus reducing the photosynthetic activity and due to this reason the microalgal cells try to get energy through heterotrophic metabolism for being able to maintain its viability.

To sum up, the presence of atrazine leads to an increase in the cellular ROS levels that can be related to a decrease in chlorophyll content and, hence, in a decrease in the photosynthetic activity that can enhance the ROS production, as a loop. Furthermore, this herbicide causes photosynthetic adjustments in $C$. reinhardtii cells based on alterations observed in transcriptomic profile as well as the disappearance of some photosynthesis-related proteins. On the one hand, levels of transcripts encoding for chlorophyll binding proteins, components of the PSII and carbonic anhydrases, which help increase the $\mathrm{CO}_{2}$ concentration in the chloroplast, were reduced. On the other hand, some transcripts encoding for $C_{i}$ transporters were upregulated as a cell response to acclimation to stress provoked by the herbicide. Moreover, the amount of PSIl component proteins, a chloroplast ATP synthase and a carbonic anhydrase, an important regulatory protein in carbon fixation process, decreased due to the stress caused by this herbicide.

\section{Conclusions}

A sublethal concentration of atrazine $(0.25 \mu \mathrm{M})$ alters the transcriptomic and proteomic profile of Chlamydomonas reinhardtii cells. Using flow cytometry protocols a decrease in chlorophyll a fluorescence and an increase in intracellular ROS levels were detected in atrazine exposed cells with respect to control cells. A reduction in cellular pigment contents was also observed in exposed cultures. Transcriptomic analyses advance the understanding of photosynthetic adjustments that occur during herbicide 
exposure. Inhibition of photosynthesis induced by atrazine toxicity will affect the entire physiological and biochemical states of microalgal cells. Protein profile was also altered by the atrazine stress. Taking into account these results, the increase in some pollutants in aquatic systems could lead to a dramatic decrease in $\mathrm{CO}_{2}$ fixation at a global level.

\section{Acknowledgements}

This work was carried out with the financial support of the Spanish Ministerio de Economía y Competitividad (CGL2010-15993/BOS). M.E. and M.S. acknowledge their pre-doctoral fellowship from the Xunta de Galicia (Spain).

\section{References}

Adamska, I., 1997. ELIPs-light-induced stress proteins. Physiol. Plant. 100, 794-805.

Adamska, I., 2001. The Elip family of stress proteins in the thylakoid membranes of proand eukaryota. In: Aro, E.M., Andersson, B. (Eds.), Advances in Photosynthesis and

Respiration-Regulation of Photosynthesis vol. 11. Kluwer Academic Publishers, Dordrecht, pp. 487-505.

Aluru, M.R., Rodermel, S.R., 2004. Control of chloroplast redox by the IMMUTANS terminal oxidase. Physiol. Plant. 120, 4-11.

Badger, M.R., Price, G.D., 2003. CO2 concentrating mechanisms in cyanobacteria: molecular components, their diversity and evolution. J. Exp. Bot. 54, 609-622.

Bi Fai, P., Grant, A., Reid, B., 2007. Chlorophyll a fluorescence as a biomarker for rapid toxicity assessment. Environ. Toxicol. Chem. 26, 1520-1531.

Bonente, G., Ballottari, M., Truong, T.B., Morosinotto, T., Ahn, T.K., Fleming, G.R., Niyogi, K.K., Bassi, R., 2011. Analysis of LhcSR3, a protein essential for feedback de-excitation in the green alga Chlamydomonas reinhardtii. PLoS Biol. 9, e1000577.

Brack,W., Frank, H., 1998. Chlorophyll a fluorescence: a tool for the investigation of toxic effects in the photosynthetic apparatus. Ecotoxicol. Environ. Saf. 40, 34-41.

Campanella, L., Cubadda, F., Sammartino, M.P., Saoncella, A., 2001. An algal biosensor for the monitoring of water toxicity in estuarine enviroments. Water Res. 35, 69-76.

Carol, P., Kuntz, M., 2001. A plastid terminal oxidase comes to light: implications for carotenoid biosynthesis and chlororespiration. Trends Plant Sci. 6, 31-36.

Chalifour, A., Spear, P.A., Boily, M.H., DeBlois, C., Giroux, I., Dassylva, N., Juneau, P., 2009. Assessment of toxic effects of pesticide extracts on different green algal species by using chlorophyll a fluorescence. Toxicol. Environ. Chem. 91, 1315-1329. 
Chekounova, E., Voronetskaya, V., Papenbrock, J., Grimm, B., Beck, C.F., 2001. Characterization of Chlamydomonas mutants defective in the $\mathrm{H}$ subunit of $\mathrm{Mg}$-chelatase. Mol. Gen. Genomics. 266, 363-373.

Choi, C.J., Berges, J.A., Young, E.B., 2012. Rapid effects of diverse toxic water pollutants on chlorophyll a fluorescence: variable responses among freshwater microalgae. Water Res. 46, 2615-2626.

Chou, T.C., Martin, N., 2005. CompuSyn for Drug Combinations: PC Software and User's Guide: A Computer Program for Quantification of Synergism and Antagonism in Drug Combinations and the Determination of IC50 and ED50 and LD50 Values. ComboSyn, Inc., Paramus, NJ.

Cid, Á., Herrero, C., Torres, E., Abalde, J., 1995. Copper toxicity on the marine microalga Phaeodactylum tricornutum: effects on photosynthesis and related parameters. Aquat. Toxicol. 31, 165-174.

Couderchet, M., Vernet, G., 2003. Pigments as biomarkers of exposure to the vineyard herbicide flazasulfuron in freshwater algae. Ecotoxicol. Environ. Saf. 55, 271-277.

Damerval, C., DeVienne, D., Zivy, M., Thiellement, H., 1986. Technical improvements in twodimensional electrophoresis increase the level of genetic variation detected in wheat seedling proteins. Electrophoresis 7, 52-54.

Didur, O., Perreault, F., Oukarroum, A., Dewez, D., Popovic, R., 2012. Alteration of photosystem II activity by atrazine on Chlamydomonas reinhardtii synchronized and asynchronized cell cycle cultures. Toxicol. Environ. Chem. 94, 906-917.

Dowling, V.A., Sheehan, D., 2006. Proteomics as a route to identification of toxicity targets in environmental toxicology. Proteomics 6, 5597-5604.

Duanmu, D., Miller, A.R., Horken, K.M., Weeks, D.P., Spalding, M.H., 2009. Knockdown of limiting-CO2-induced gene $\mathrm{HLA} 3$ decreases $\mathrm{HCO} 3$ - transport and photosynthetic $\mathrm{Ci}$ affinity in Chlamydomonas reinhardtii. Proc. Natl. Acad. Sci. U. S. A. 106, 5990-5995.

Duanmu, D., Casero, D., Dent, R.M., Gallaher, S., Yang, W., Rockwell, N.C., Lagarias, J.C., 2013. Retrograde bilin signaling enables Chlamydomonas greening and phototrophic survival. PNAS 110, 3621-3626.

Ekelund, N.G.A., Aronson, K.A., 2007. Changes in chorophyll a fluorescence in Euglena gracilis and Chlamydomonas reinhardtii after exposure to wood-ash. Environ. Exp. Bot. 59, 9298.

Ekmekci, Y., Terzioglu, S., 2005. Effects of oxidative stress induced by paraquat on wild and cultivated wheat. Pestic. Biochem. Physiol. 83, 69-71.

Eriksson, M., Gardestrom, P., Samuelsson, G., 1995. Isolation, purification, and characterization of mitochondria from Chlamydomonas reinhardtii. Plant Physiol. 107, 479-483.

Eriksson, M., Karlsson, J., Ramazanov, Z., Gardestrom, P., Samuelsson, G., 1996. Discovery of an algal mitochondrial carbonic anhydrase:molecular cloning and characterization of a low-CO2-induced polypeptide in Chlamydomonas reinhardtii. Proc. Natl. Acad. Sci. U. S. A. $93,12031-12034$. 
Esperanza,M., Seoane, M., Rioboo, C., Herrero, C., Cid, Á., 2015. Chlamydomonas reinhardtii cells adjust themetabolismto maintain viability in response to atrazine stress. Aquat. Toxicol. 165, 64-72.

European Council, 2013. Directive 2013/39/EC of the European Parliament and of the Council of 12 August 2013 Amending Directives 200/30/EC and 2008/105/EC as Regards Priority Substances in the Field of Water Policy.

Fernández-Puente, P., Máteos, J., Fernández-Costa, C., Oreiro, N., Fernández-López, C., RuizRomero, C., Blanco, F.J., 2011. Identification of a panel of novel serum osteoarthritis biomarkers. J. Proteomics Res. 10, 5095-5101.

Förster, B., Mathesius, U., Pogson, B.J., 2006. Comparative proteomics of high light stress in the model alga Chlamydomonas reinhardtii. Proteomics 6, 4309-4320.

Franklin, N.M., Adams, M.S., Stauber, J.L., Lim, R.P., 2001. Development of an improved rapid enzyme inhibition bioassay with marine and freshwater microalgae using flow cytometry. Arch. Environ. Contam. Toxicol. 40, 469-480.

Gayoso, C.M., Mateos, J., Méndez, J.A., Fernández-Puente, P., Rumbo, C., Tomás, M., Martínez de llarduya, O., Bou, G., 2014. Molecular mechanisms involved in the response to desiccation stress and persistence in Acinetobacter baumannii. J. Proteome Res. 13, 276-460.

Geoffroy, L., Gilbin, R., Simon, O., Floriani, M., Adam, C., Pradines, C., Cournac, L., GarnierLaplace, J., 2007. Effect of selenate on growth and photosynthesis of Chlamydomonas reinhardtii. Aquat. Toxicol. 83, 149-158.

Giordano, M., Norici, A., Forssen,M., Eriksson,M., Raven, J.A., 2003. An anaplerotic role for mitochondrial carbonic anhydrase in Chlamydomonas reinhardtii. Plant Physiol. 132, 2126-2134.

González-Barreiro, O., Rioboo, C., Cid, A., Herrero, C., 2004. Atrazine-induced chlorosis in Synechococcus elongatus cells. Arch. Environ. Contam. Toxicol. 46, 301-307.

Harris, E.H., 1989. The Chlamydomonas Sourcebook: A Comprehensive Guide to Biology and Laboratory Use. Academic Press, San Diego.

Havaux, M., 2003. Spontaneous and thermoinduced photon emission: new methods to detect and quantify oxidative stress in plants. Trends Plant Sci. 8, 409-413.

Hayes, T.B., Khoury, V., Narayan, A., Nazir, M., Park, A., Brown, T., Adame, L., Chan, E., Buchholz, D., Stueve, T., Gallipeau, S., 2010. Atrazine induces complete feminization and chemical castration in male African clawed frogs (Xenopus laevis). PNAS 107, 46124617.

Hemschemeier, A., Casero, D., Liu, B., Benning, C., Pellegrini, M., Happe, T., Merchant, S.S., 2013. Copper response regulator1-dependent and -independent responses of the Chlamydomonas reinhardtii transcriptome to dark anoxia. Plant Cell 25, 3186-3211.

Houille-Vernes, L., Rappaport, F., Wollman, F., Alric, J., Johnson, X., 2011. Plastid terminal oxidase 2 (PTOX2) is the major oxidase involved in chlororespiration in Chlamydomonas. PNAS 108, 20820-20825. 
Huang, S., Hainzl, T., Grundström, C., Forsman, C., Samuelsson, G., Sauer-Eriksson, A.E., 2011. Structural studies of $\beta$-carbonic anhydrase from the green alga coccomyxa: inhibitor complexes with anions and acetazolamide. PLoS ONE 6, e28458.

Hutin, C., Nussaume, L., Moise, N., Moya, I., Kloppstech, K., Havaux, M., 2003. Early lightinduced proteins protect Arabidopsis from photooxidative stress. Proc. Natl. Acad. Sci. U. S. A. 100, 4921-4926.

Iwai, M., Kato, N., Minagawa, J., 2007. Distinct physiological responses to a high light and low $\mathrm{CO} 2$ environment revealed by fluorescence quenching in photoautotrophically grown Chlamydomonas reinhardtii. Photosynth. Res. 94, 307-314.

Jamers, A., De Coen,W., 2010. Effect assessment of the herbicide paraquat on a green alga using differential gene expression and biochemical biomarkers. Environ. Toxicol. Chem. 29, 893-901.

Jamers, A., Blust, R., De Coen, W., 2009. Omics in algae: paving the way for a systems biological understanding of algal stress phenomena? Aquat. Toxicol. 92, 114-121.

Jeffrey, S.W., Humphrey, G.F., 1975. New spectrophotometric equations for determining chlorophylls a, b, c1 and c2 in higher plants, algae and natural phytoplankton. Biochem. Physiol. Pflanz. 167, 191-194.

Johnson, X., Alric, J., 2013. Central carbon metabolism and electron transport in Chlamydomonas reinhardtii: metabolic constraints for carbon partitioning between oil and starch. Eukaryot. Cell 12, 776-793.

Juneau, P., El Berdey, A., Popovic, R., 2002. PAM fluorometry in the determination of the sensitivity of Chlorella vulgaris, Selenastrum capricornutum, and Chlamydomonas reinhardtii to copper. Arch. Environ. Contam. Toxicol. 42, 155-164.

Jungnick, N., Ma, Y., Mukherjee, B., Cronan, J.C., Speed, D.J., Laborde, S.M., Longstreth, D.J., Moroney, J.V., 2014. The carbon concentrating mechanism in Chlamydomonas reinhardtii: finding the missing pieces. Photosynth. Res. 121, 159-173.

Król, M., Ivanov, A.G., Jansson, S., Kloppstech, K., Huner, N.P.A., 1999. Greening under high light or cold temperature affects level of xanthophyll cycle pigments, early lightinducible proteins, and light-harvesting polypeptides in wild-type barley and the chlorina 22 mutant. Plant Physiol. 120, 193-203.

Lackner, D., Schmidt, M., Wu, S., Wolf, D., Bähler, J., 2012. Regulation of transcriptome, translation, and proteome in response to environmental stress in fission yeast. Genome Biol. 13, 1-14.

Laloi, C., Apel, K., Danon, A., 2004. Reactive oxygen signalling: the latest news. Curr. Opin. Plant Biol. 7, 323-328.

Lers, A., Levy, H., Zamir, A., 1991. Co-regulation of a gene homologous to early lightinduced genes in higher plants and $\beta$-carotene biosyn- thesis in the alga Dunaliella bardawil. J. Biol. Chem. 266, 13698-13705.

Levy, H., Tal, T., Shaish, A., Zamir, A., 1993. Cbr, an algal homolog of plant early lightinduced proteins, is a putative zeaxanthin-binding protein. J. Biol. Chem. 268, 20892-20896. 
Liu, W., Ming, Y., Huang, Z., Li, P., 2012. Impacts of florfenicol on marine diatom Skeletonema costatum through photosynthesis inhibition and oxidative damages. Plant Physiol. Biochem. 60, 165-170.

Lopez, D., Casero, D., Cokus, S.J., Merchant, S.S., Pellegrini, M., 2011. Algal functional annotation tool: a web-based analysis suite to functionally interpret large gene lists using integrated annotation and expression data. BMC Bioinforma. 12, 282.

Ma, J.,Wang, S.,Wang, P.,Ma, L., Chen, X., Xu, R., 2006. Toxicity assessment of 40 herbicides to the green alga Raphidocelis subcapitata. Ecotoxicol. Environ. Saf. 63, 456-462.

Marchetti, G., Minella, M., Maurino, V., Minero, C., Vione, D., 2013. Photochemical transformation of atrazine and formation of photointermediates under conditions relevant to sunlit surface waters: laboratory measures and modeling. Water Res. 47, 6211-6222.

Martinez, R.S., Di Marzio, W.D., Sáenz, M.E., 2014. Genotoxic effects of commercial formulations of Chlorpyrifos and Tebuconazole on green algae. Ecotoxicology 24, 45-54.

Maruyama, S., Tokutsu, R., Minagawa, J., 2014. Transcriptional regulation of the stressresponsive light harvesting complex genes in Chlamydomonas reinhardtii. Plant Cell Physiol. 55, 1304-1310.

McKay, R.M.L., Gibbs, S.P., Vaughn, K.C., 1991. RuBisCo activase is present in the pyrenoid of green algae. Protoplasma 162, 38-45.

Melegari, S.P., Perreault, F., Costa, R.H.R., Popovic, R., Matias, W.G., 2013. Evaluation of toxicity and oxidative stress induced by copper oxide nanoparticles in the green alga Chlamydomonas reinhardtii. Aquat. Toxicol. 142-143, 431-440.

Merchant, S.S., Prochnik, S.E., Vallon, O., Harris, E.H., Karpowicz, J.,Witman, G.B., Terry, A., Salamov, A., Fritz-Laylin, L.K., Marechal-Drouard, L., et al., 2007. The Chlamydomonas genome reveals the evolution of key animal and plant functions. Science 318, 245-250.

Miura, K., Yamano, T., Yoshioka, S., Kohinata, T., Inoue, Y., Taniguchi, F., Asamizu, E., Nakamura, Y., Tabata, S., Yamato, K.T., Ohyama, K., Fukuzawa, H., 2004. Expression profiling-based identification of CO2-responsive genes regulated by CCM1 controlling a carbon-concentrating mechanism in Chlamydomonas reinhardtii. Plant Physiol. 135, 1595-1607.

Mofeed, J., Mosleh, Y.Y., 2013. Toxic responses and antioxidative enzymes activity of Scenedesmus obliquus exposed to fenhexamid and atrazine, alone and in mixture. Ecotoxicol. Environ. Saf. 95, 234-240.

Monsinjon, T., Knigge, T., 2007. Proteomic applications in ecotoxicology. Proteomics 7, 29973009.

Montané,M.H., Kloppstech, K., 2000. The family of light-harvesting-related proteins (LHCs, ELIPs, HLIPs): was the harvesting of light their primary function? Gene 258, 1-8.

Moroney, J.V., Ynalvez, R.A., 2007. Proposed carbon dioxide concentrating mechanism in Chlamydomonas reinhardtii. Eukaryot. Cell 6, 1251-1259.

Moroney, J.V., Ma, Y., Frey,W.D., Fusilier, K.A., Pham, T.T., Simms, T.A., DiMario, R.J., Yang, J., Mukherjee, B., 2011. The carbonic anhydrase isoforms of Chlamydomonas reinhardtii: 
intracellular location, expression, and physiological roles. Photosynth. Res. 109, 133149.

Nestler, H., Groh, K.J., Schönenberger, R., Eggen, R.I.L., Suter,M.J.F., 2012. Linking proteome responses with physiological and biochemical effects in herbicide-exposed Chlamydomonas reinhardtii. J. Proteome 75, 5370-5385. 